\title{
STRATEGI ADAPTASI KAMPUNG TERHADAP KENAIKAN AIR LAUT DAN PENURUNAN TANAH DI MUARA ANGKE
}

\author{
Abigael Mardianto ${ }^{1)}$, Martin Halim ${ }^{2)}$ \\ 1)Program Studi S1 Arsitektur, Fakultas Teknik, Universitas Tarumanagara, abigaelmardi@gmail.com \\ 2) Program Studi S1 Arsitektur, Fakultas Teknik, Universitas Tarumanagara, martinhalim90@gmail.com \\ Masuk: 03-07-2021, revisi: 15-08-2021, diterima untuk diterbitkan: 23-10-2021
}

\begin{abstract}
Abstrak
Jakarta menjadi kota yang paling cepat tenggelam di dunia, khususnya area Jakarta Utara dengan rata-rata permukaan tanah sudah berada lebih dari 1,5 $\mathrm{m}$ di bawah permukaan laut. Penelitian menunjukan bahwa di tahun 2050 95\% area Jakarta Utara akan berada lebih dari $4 \mathrm{~m}$ dibawah permukaan laut. Dengan melihat permasalahan tersebut rumah dan mata pencaharian warga Muara Angke, Jakarata Utara sedang dan semakin tenggelam. Selain itu ekosistem pesisir yang merupakan hutan mangrove, rumah untuk banyak jenis flora dan fauna juga terancam tenggelam. Kebutuhan akan bentuk bangunan baru yang dapat mengatasi permasalahan ini secara menyeluruh bukan sementara seperti tanggul-tanggul yang dibangun oleh pemerintah saat ini. Metode perancangan yang digunakan melalui studi litelatur, studi presenden, adaptasi, dan modular menjadi dasar dari desain bangunan. Strategi desain yang sesuai dengan cara hidup masnyarakat Muara Angke dan adaptif terhadap kenaikan air laut dengan menggunakan teknologi struktur kombinasi kolom teleskopik yang adjustable dan platform apung terbuat dari daur ulang galon plastik menjadikan lingkungan tahan terhadap perubahan iklim. Bangunan dapat menyesuaikan dengan berbagai fase kenaikan air laut yaitu pada saat pasang,surut dan tenggelam. Proyek ini bertujuan memberikan hunian yang adaptif terhadap perubahan iklim serta mengembalikan keseimbangan ekosistem pesisir Muara Angke.
\end{abstract}

\section{Kata kunci: Adaptif; ekosistem pesisir; kebutuhan hunian; mangrove; Muara Angke}

\begin{abstract}
The capital city of Indonesia, Jakarta, is the world's fastest sinking city, especially the Northern part with an average land surface of more than 1.5 metres below sea level. Research shows that about 95\% of North Jakarta will be 4 metres or far more below sea level by 2050. Sinking land jeopardises the Angke Estuary community since people lose their homes and livelihoods. Additionally, the mangrove forests in the coastal areas are home to many flora and fauna and now at risk due to drowning. Therefore, innovation in building structure would potentially mitigate instead of remediating the current issues. The design method used in literature and precedent studies, adaptation, and modular design become the basis of building design. A Telescopic column is an adjustable-floating system made out of recycled gallon plastic containers. It is an innovative and clean approach because of its sustainability towards climate change and environmentally friendly by utilising recycled material. The floating feature enables the building to adapt to sea-level fluctuations (e.g. high - low tides). This project aims to provide better living areas for the marginal communities of Angke Estuary whilst restore the coastal ecosystems.
\end{abstract}

Keywords: Adaptive; coastal ecosystem; mangrove; Muara Angke; residential needs

\section{PENDAHULUAN}

\section{Latar Belakang}

Dalam seabad terakhir, aktifitas manusia seperti pembakaran bahan bakar fosil telah melepas sejumlah heat-trapping gases ke atmosfer. Gas buangan tersebut menyebabkan suhu permukaan bumi meningkat dan laut menyerap $80 \%$ dari panas tersebut. Panas yang 
diserah oleh laut menyebabkan kenaikan yang signifikan pada permukaan air laut. Bahkan jika gas emisi pemanasan global dapat turun hingga $0 \%$. Peneliti menyatakan permukaan air laut akan tetap naik di 1.2-2.6 kaki ditahun 2100. Penggunaan air tanah secara illegal dan terus menerus juga membuat penurunan tanah meningkat tajam dalam satu dekade terakhir. Naiknya permukaan air laut akibat pemanasan global dan penurunan tanah menjadi penyebab terendamnya beberapa area pesisir utama. Penelitian baru menunjukan bahwa 150 juta orang di dunia saat ini tinggal di darat akan berada di bawah garis pasang laut pada tahun 2050.

Hampir setengah populasi di dunia tinggal diarea pesisir. Masnyarakat yang tinggal di area pesisir tersebut merupakan penghasil $80 \%$ dari PDB global.Indonesia sebagai negara kepulauan terbesar di dunia telah kehilangan daratan sebesar Jakarta dalam 15 tahun terakhir. Dimana 23 juta orang di kota pesisir Indonesia terancam kehilangan tempat tinggal mereka ditahun 2050. Pulau Jawa menjadi pulau dengan area erosi terluar di Indonesia dengan luas erosi 3.069 ha untuk Jawa barat. Kota jakarta sebagai ibu kota Indonesia menjadi kota paling cepat tenggelam didunia. Diperkirakan 95\% area Jakarta Utara akan tenggelam tepatnya di kawasan Muara Angke yang saat ini letak nya sudah berada $1,5 \mathrm{~m}$ di bawah permukaan air laut. Selama bertahun-tahun daratan yang merupakan hunian dan lahan pekerjaan warga telah tenggelam dan diperkirakan akan tenggelam lebih banyak lagi. Menjadi sebuah tantangan untuk beradaptasi dengan kesulitan yang sudah terjadi dan mempersiapkan ketahanan untuk masa depan.

\section{Rumusan Permasalahan}

Melihat dampak perubahan iklim yang ekstrim terhadap lingkungan secara arsitektural, maka fokus utama adalah penyediaan tempat tinggal yang adaptif bagi warga Muara Angke. Setelah memiliki tempat tinggal, maka tempat tinggal seperti apakah yang harus diberikan kepada masnyarakat pesisir. Kedua hal ini tentunya harus mempertimbangkan gaya hidup, karakter dan aktifitas keseharian warga. Selain itu, bagaimapun rancangan dari tempat tinggal harus dapat dijangkau oleh warga secara finansial. Sehingga yang menjadi pertanyaan utama adalah bagaimana merancang permukiman bagi warga yang adaptif dengan tetap menghadirkan karakteristik masyarakat Muara Angke

\section{Tujuan}

Berdasarkan rumusan masalah yang ada, proyek ini memberikan solusi berupa penyedian hunian dan program pendukung hunian yang relevan dengan struktur bangunan yang modular dan adaptif. Struktur bangunan yang dapat dibangun secara mandiri oleh masnyarakat dengan material yang terjangkau seperti galon plastik bekas sebagai media apung utama.

Penggunaan kombinasi teleskopik kolom dan platform apung menjadikan bangunan dapat mengikuti kenaikan air laut pada saat pasang, surut, dan tenggelam. Dengan kehadiran proyek ini dapat menyelesaikan permasalahan kehilangan permukiman dan mata pencaharian warga Muara Angke serta menciptakan keseimbangan ekosistem pesisir Muara Angke .

\section{KAJIAN LITERATUR}

\section{The Salty Urbanism}

Berdasarkan penelitian yang dilakukan AIA (2008) berjudul the Salty Urbanism (Gambar 1) terdapat 8 cara bangunan menghadapi pertemuan kota dan air yaitu (1) Abandon, dengan meninggalkan bangunan dan memperbaikinya dengan reklamasi. (2) Flood proofing building, menggunakan material tahan air pada finishing bangunan. (3) Flood proofing site, membangun struktur tembok yang mengelilingi tapak. (4) Retreat, Re-lokasi atau memindahkan bangunan ke daerah yang kering. (5) Raised mound, Meninggikan bangunan dari tanah agar air tidak masuk kedalam bangunan namun cara ini tidak ramah terhadap erosi pesisir, pembangunan 
masa depan, dan kenaikan air laut. (6) Raised stilts, Menaikan bangunan dengan sistem panggung . (7) Amphibious structurey, Struktur bangunan dibangun diatas air yang dapat mengesuaikan dengan kenaikan air.(8) Floating structure Struktur bangunan yang mengapung diatas air serta dapat bergerak bebas menyesuaikan dengan arah arus air.

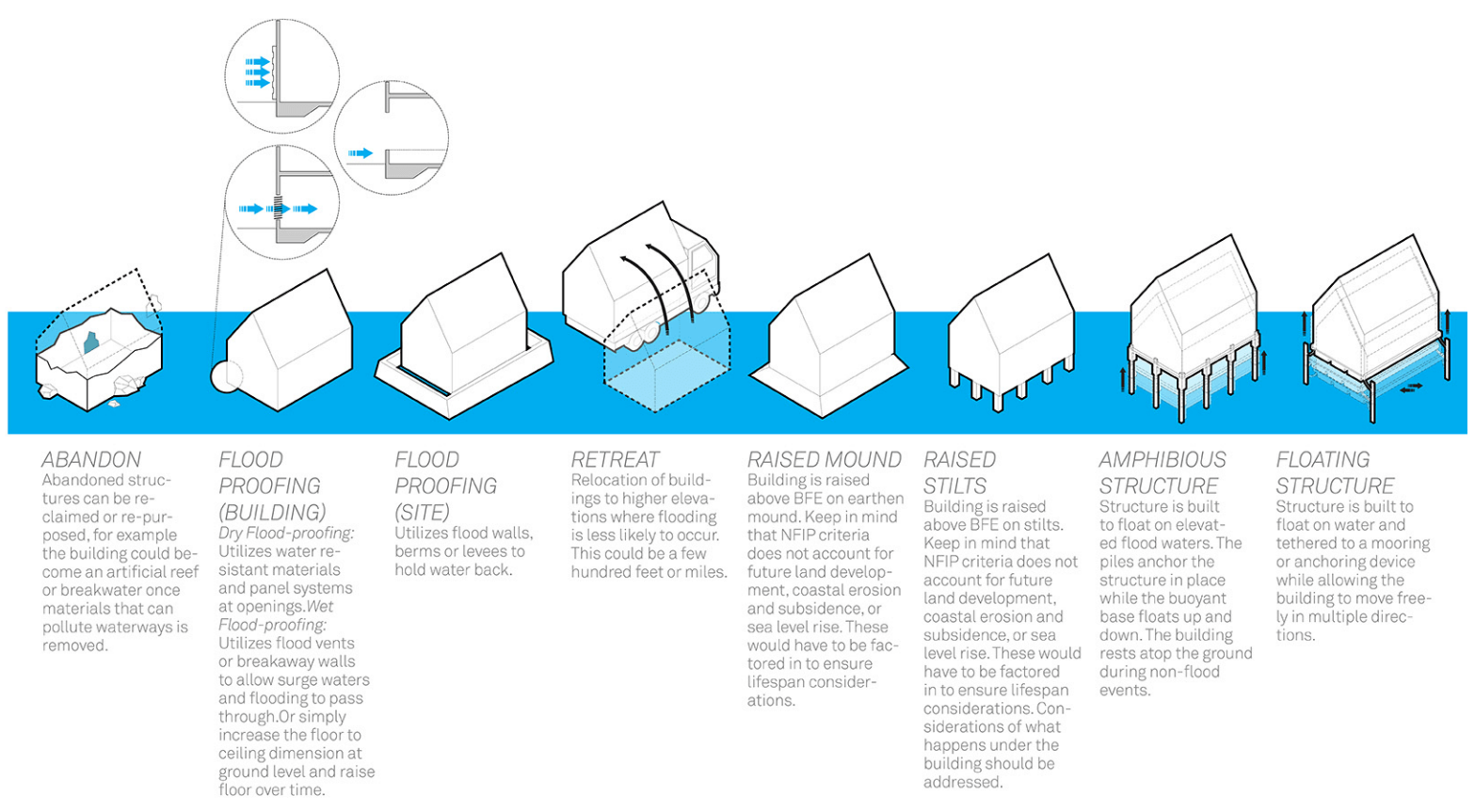

Gambar 1. Sea Level Rise Adaptation Strategies for Urban Areas Sumber: aia.org

\section{Kiribati Floating House}

Studi perancangan karya arsitek Havi Koslawasky (2019) menjadi salah satu kajian dalam melakukan riset proyek tugas akhir. Proyek ini berupa hunian apung dengan struktur kolom telescopik dengan hunian tradisional kepulauan Kiribati. Menjadikan proyek ini perpaduan antara hunian tradisional dan teknologi masa kini.

\section{Foolding Tools for Kerala}

Dibuat oleh Omar Andreas Campos Rivera, sebagai ringkasan atau dasar singkat pembuatan hunian modular yang dapat dibangun secara mandiri oleh masnyarakat kerala. Pada proyek ini dijelaskan detail struktur bangunan amfibi, dengan material galon plastik dan pondasi beton sebagai pengikat dan disatukan dengan struktur dinding bamboo yang ringgan membuat bangunan mudah terangkat.

\section{Water no get enemy- Monopile Telescopic Column}

Rancangan Lloyd Martin, menjadi kajian dalam melakukan riset proyek tugas akhir. Studi rancangan ini menggunakan struktur monopole telescopic column dengan pipa flexsible dan dilengkapi dengan rain water harvesting atau wind generators pada bagian atap tiap hunian sehingga setiap hunian dapat menghasilkan energi listrik dan sumber air bersih secara mandiri. Menjadikan proyek ini hunian sangat berkelanjutan. 


\section{LAGOS: CITY OF WATER}

Sisten sir $t$ ktur kolurn yally ad- MONOPILE - TELESCOPC COLUMN

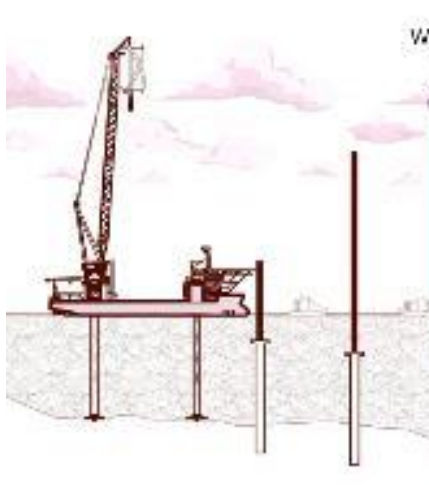

Vind-generators menglkiti kenakal alriat
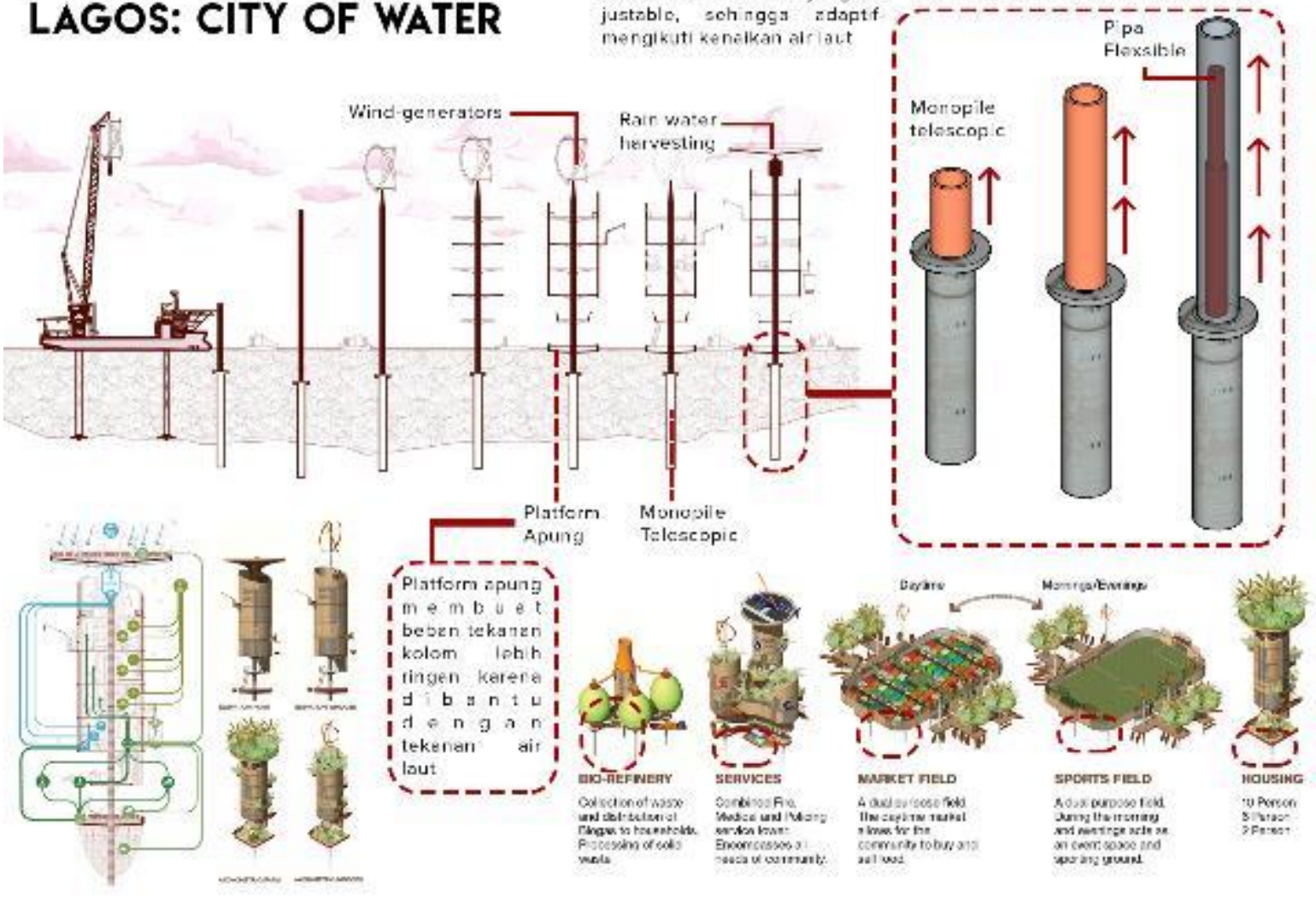

Gambar 2. Sea Level Rise Adaptation Strategies for Urban Areas

Sumber: Penulis, 2021

\section{METODE}

Metode perancangan yang digunakan dalam proyek ini adalah:

\section{a. Studi Literatur}

Studi literature diambil dari penelitian AIA dengan judul the Salty Urbanism yang menjadi landasan starategi adaptasi kampung terhadapat kehilangan daratan pesisir yang menjadi landasan pemahaman mengenai 'melampaui' ekologi dan dasar pengangkatan isu 'kehilangan daratan pesisir'

b. Studi Preseden

Karya arsitektur yang dipakai sebagai refensi proyek tugas akhir ini adalah Kiribari Floating House Competiton, Foolding Tools for Kerala, dan Lagos: Water of City

c. Adaptasi dan Ketahanan

Proyek ini didesain menggunakan metode adaptasi bangunan yang secara struktur memiliki ketahaan terhadap bencana terutama tahan terhadap kenaikan air laut. Dengan struktur bangunan yang adaptif dan dapat dimenyesuaikan dengan kenaikan muka air laut.

d. Modular dan Fleksibel

Desain bangunan yang modular dan fleksibel digunakan agar bangunan dapat direplikasi dan dibangun dengan mudah seiring dengan bertambahnya area pesisir yang tenggelam dari tahun ke tahun. 


\section{DISKUSI DAN HASIL}

\section{Kondisi Muara Angke}

Tapak terpilih terletak di kawasan Muara Angke, kelurahan Pluit, Kecamatan Penjaringan, Jakarta Utara yang menjadi salah satu daerah terdampak kehilangan daratan pesisir secara signifikan. Tapak ini dipilih karena memiliki kecocokan dengan isu yang diangkat berupa kehilangan darata pesisir. Tapak merupakan lahan pemukiman warga seluas $21.326 \mathrm{~m} 2$ yang dihuni oleh $153 \mathrm{kk}$ atau setara dengan 612 jiwa yang sedang dan akan terus mengalami penenggelaman daratan secara signifikan dari tahun ke tahun. Kondisi lahan yang saat ini sudah berda di $1.5 \mathrm{~m}$ di bawah permukaan air laut masih dapat bertahan karena adanya tanggul. Namun dapat dilihat pada perbandingan peta eksisting dan rencana kota (Gambar 3) memperlihatkan lahan seluas 2,1 ha ini sepenuh nya tenggelam.
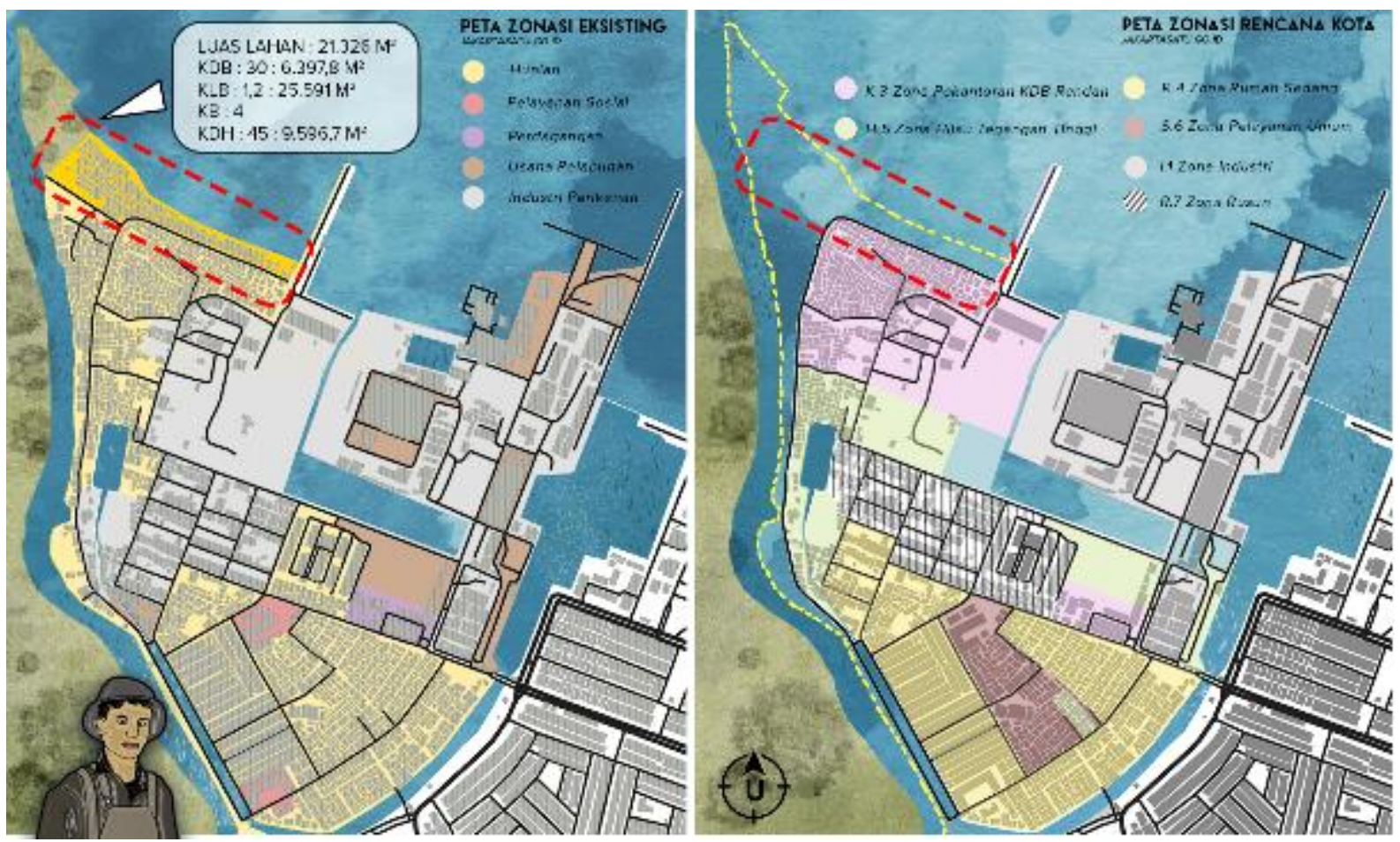

Gambar 3. Perbandingan Peta zonasi eksisting dan Peta rencana kota Sumber: Penulis, 2021

Eksisting tapak (Gambar 4) yang bersebelahan langsung dengan hutan mangrove Kali Adem menjadi salah satu ciri khas tapak. Sisi tapak yang menghadap jalan utama yaitu Jl Dermaga Ujung ditembok membuat area ini terkesan terpisah dari kawasan sekitarnya dan sering disebut sebagai Kampung Tembok. Warga hidup berdampingan dengan Hutan Mangrove Kali Adem yang saat ini sudah rusak akibat aktivitas warga yang tidak berkelanjutan. Tumpukan sampah juga memenuhi area mangrove dikarenakan objek wisata ini tidak beroperasi selama pandemic covid-19 yang membuat Hutan Mangrove Kali Adem rumah untuk banyak flora dan fauna pesisir terbengkalai.

Tapak masih dapat bertahan karena adanya tanggul di sekeliling tapak, namun air tetap mengalir melalui retakan pada tanggul yang membuat kawasan ini tidak pernah kering. Kualitas hidup yang rendah dan pola hunian yang tidak teratur dengan tingkat sanitasi rendah sangat mengkhawatirkan. Ancaman akan banjir yang tidak hanya terjadi musiman namun terjadi setiap pasang surut air laut, bahkan pada beberapa titik terus terendam air. 


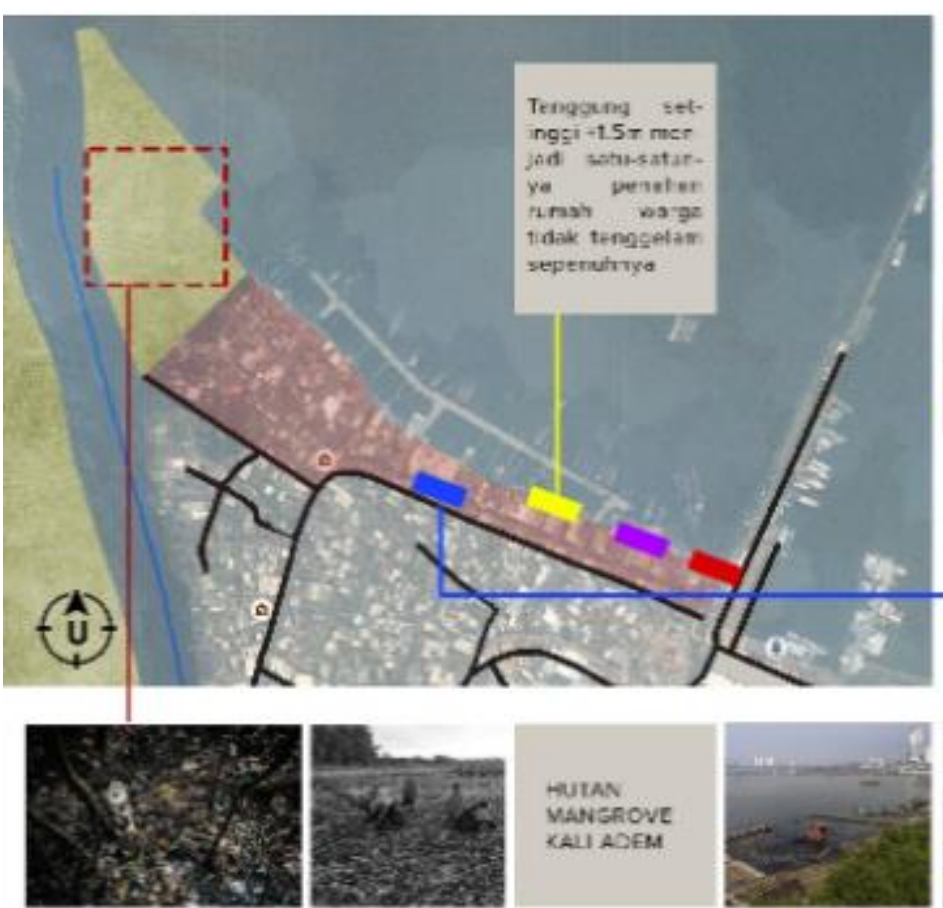

Werga hidup berdanpingen denpen tutan mangeve yerg nusk akibet acsivitas wargs tizak boree arjuts
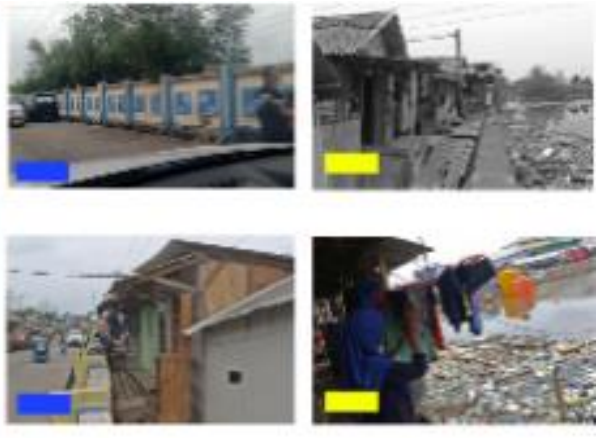

Hunian wretga ka i aders serturup terssok sering: ce ticlek teilisal leles cati Jain. Nuncul ist

Kampurg Tenhok
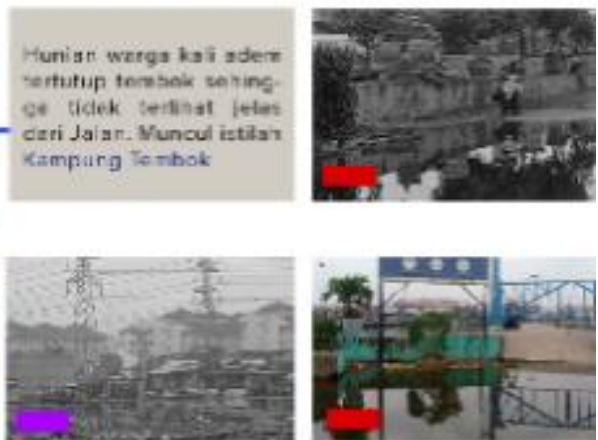

K.AMPUNG TEVEOK

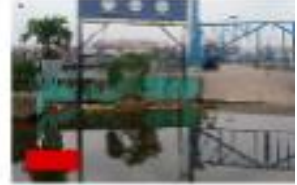

ANEA IANSSGU:

Gambar 4. Eksisting Tapak Sumber: Penulis, 2021

Lokasi tapak mengalami 3 fase berdasarkan kenaikan muka air laut (Gambar 5) yang dihadapi oleh warga setiap harinya yaitu (1) Fase surut, Keadaan saat air laut merember dari sela-sela tanggul membuat genangan air dari $5-10 \mathrm{~cm}$ pada area perumahan warga (2) Fase Pasang, Keadaan saat air laut pasang atau dikenal dengan banjir ron yang biasa dialami warga pada malam hari dan dapat menggenangi rumah mereka dari 30-90 cm. (3) Fase Tenggelam, Keadaan saat lahan tenggelam akibat kenaikan air laut dan penurunan tanah dari tahun ke tahun yang membuat warga kehilangan hunian mereka.

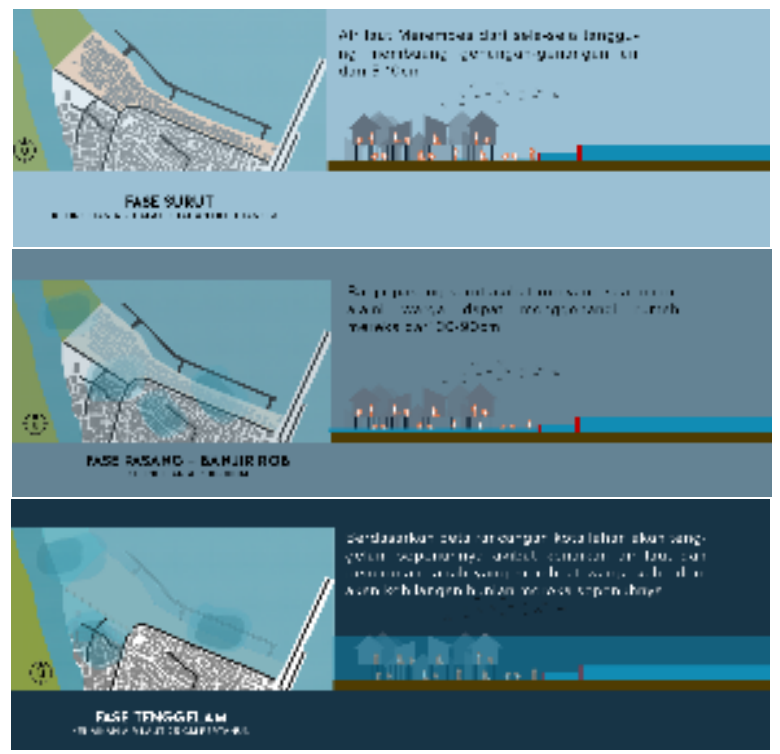

Gambar 5. Diagram Potongan Kawasan Terhadap Kenaikan Air Laut Sumber: Penulis, 2021 


\section{Pemprograman}

Program didapatkan dari hasil analisis potensi tapak yang terletak berdekatan dengan hutan mangrove dan pelabuhan Muara Angke, serta kebutuhan demografi masnyarakat setempat berdasarkan pekerjaan (Gambar 6) membutuhkan program berupa :
a. Hunian yang layak
b. Wisata edukasi mangrove
c. Area bermain anak
d. Pasar
e. Dermaga
f. Pengeringan ikan

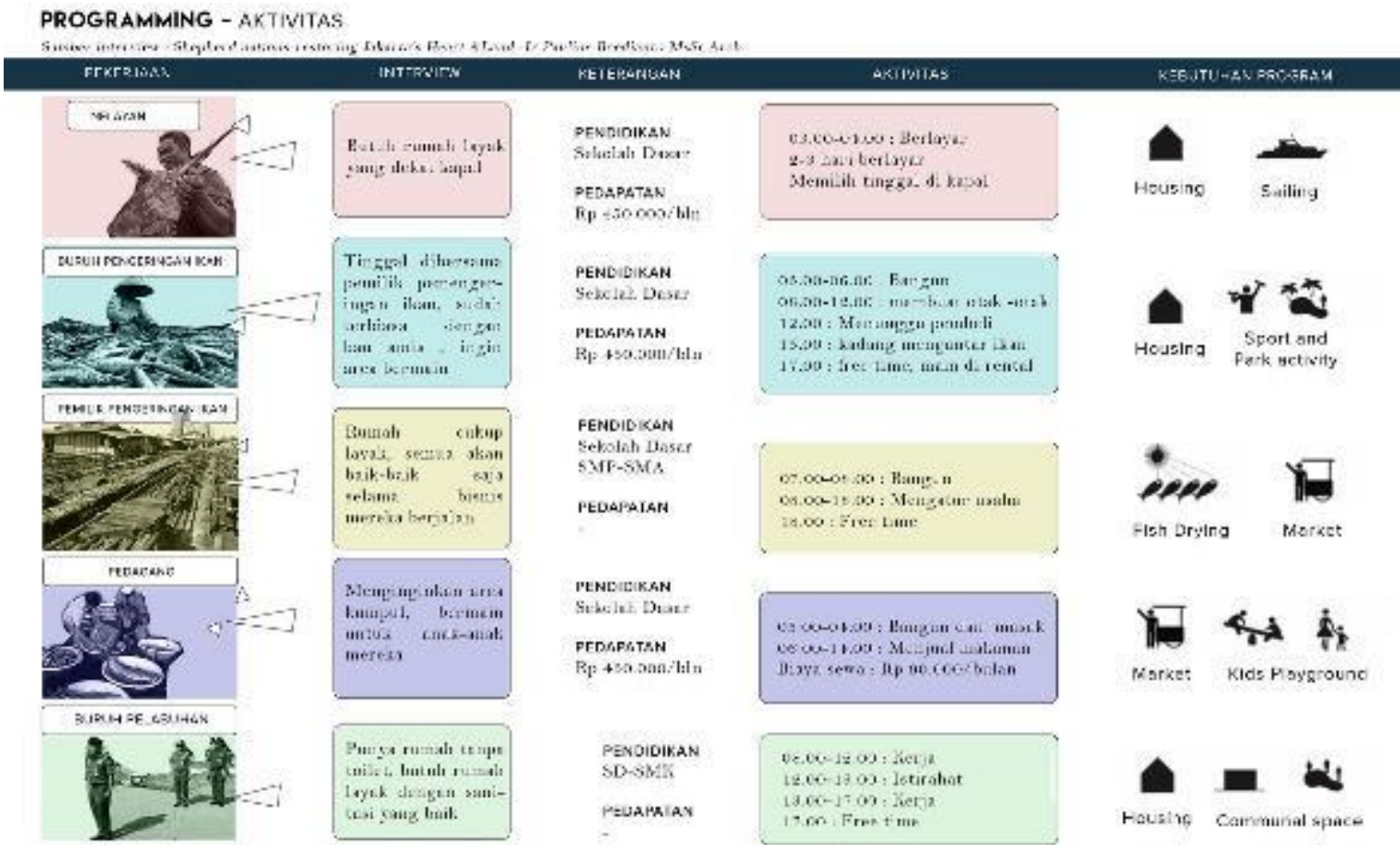

Gambar 6. Diagram Program Aktivitas

Sumber: Penulis, 2021

\section{Besaran Program}

Terdapat 3 program utama pada proyek yang didapatkan dari hasil analisis pemprograman. Setiap program saling terkait dan mewadahi aktivitas yang berbeda sesuai fungsinya. Dengan total luas bangunan $23.371 \mathrm{~m} 2$

a. Hunian

Program hunian terdiri dari lima tipe yang disesuaikan dengan jenis dan jumlah masingmasing pekerjaan warga Muara Angke terdiri dari (1) Hunian pemilik pengeringan : 34 unit (2) Hunian buruh pengeringan : 8 unit (2) Hunian buruh pelabuhan : 50 unit (3) Hunian pedagang : 23 unit (4) Hunian nelayan : 18 unit. Dengan total luasan hunian sebesar $9.880 \mathrm{~m} 2$ dan total jumlah unit 133 unit

b. Pendukung Hunian

Program pendukung hunian terdiri dari area pasar, area pengeringan ikan dan pendukung lainnya dengan luas total sebesar $7.725 \mathrm{~m} 2$.

c. Wisata edukasi mangrove

Program wisata edukasi mangrove terdiri dari area edukasi, area wisata, dan ruang pendukung dengan total luasan sebesa $5.796 \mathrm{~m} 2$ 


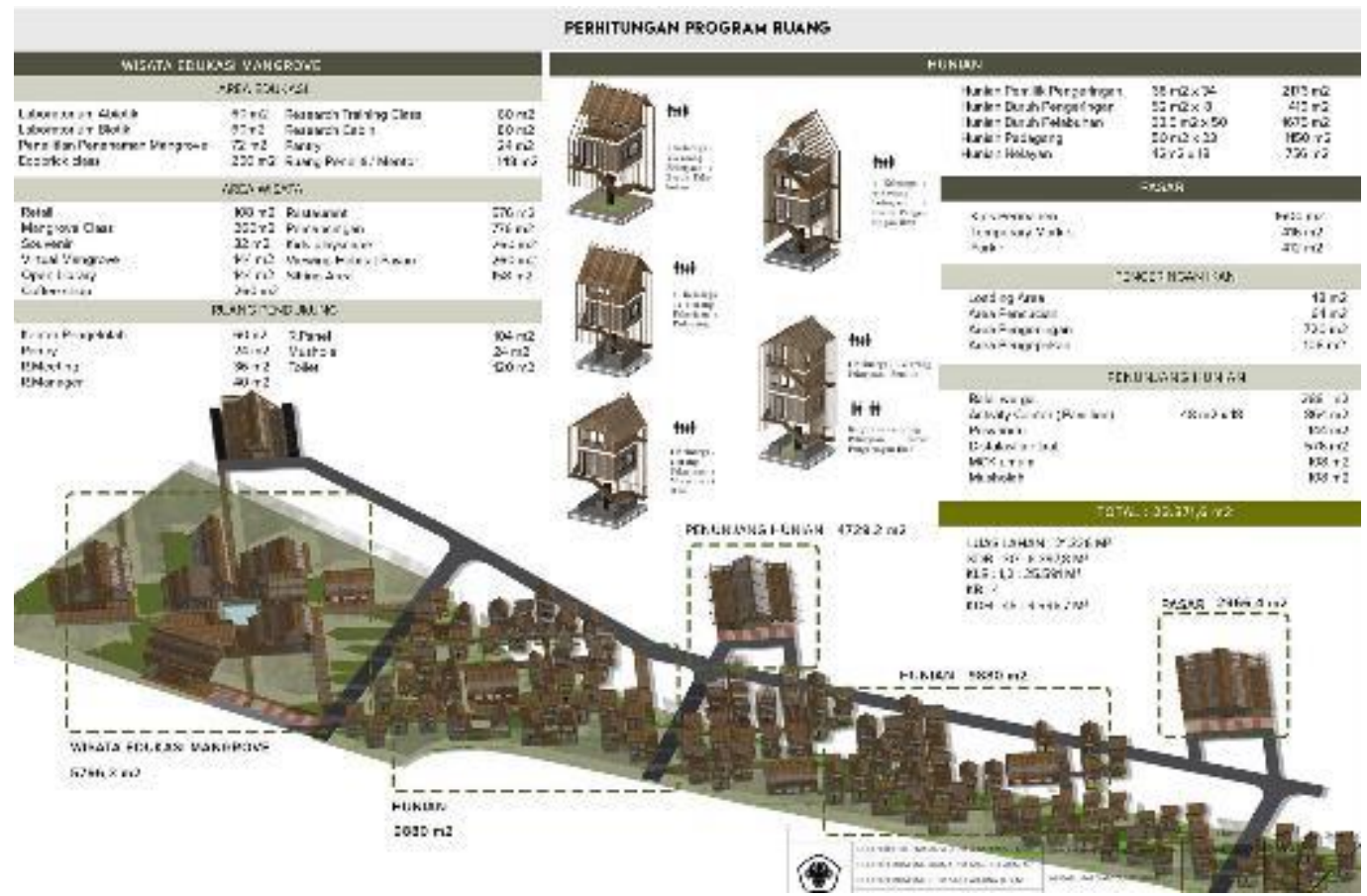

Gambar 7. Diagram Besaran Program Ruang

Sumber: Penulis, 2021

\section{Zoning Program}

Peletakan zonasi program (Gambar 8) pada tapak disesuaikan dengan analisis tapak. Analisis yang diangkat antara lain adalah (1) Program wisata edukasi mangrove diletakan berdekatan dengan Hutan Mangrove Kali Adem .(2) Hunian tipe pedagang diletakan pada jalan-jalan utama serta disekitar bangunan pasar sedangkan tipe buruh pelabuhan diletakan dibagian belakang tapak berdekatan dengan dermaga. (3) Hunian Nelayan diletakan pada tepian tapak berdampingan langsung dengan laut. (4) Pasar diletakan dekat dengan pelabuhan dan jalan utama agar mudah di akses public. (5) Pola hunian mengikuti arah matahari agar proses pengeringan ikan dapat lebih efektif.

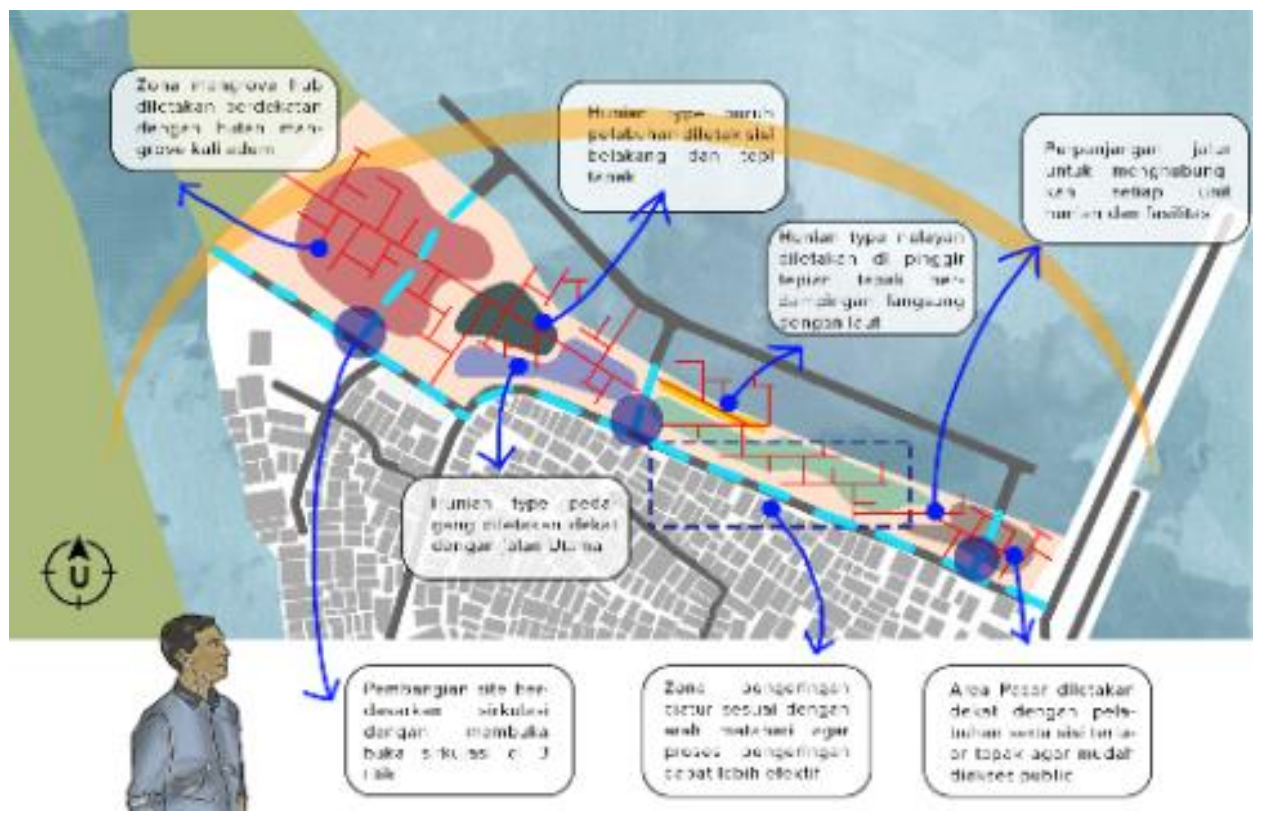

Gambar 8. Diagram Zonasi Program

Sumber: Penulis, 2021 


\section{Strategi Desain}

Untuk menghadapi 3 fase kenaikan muka air laut pada tapak (Gambar 5), strategi desain (Gambar 9) berupa sebuah lingkungan adaptif terhadap kenaikan air laut dan hilangnya daratan pesisir menjadi solusi untuk proyek ini dengan penggunaan kombinasi antara kolom teleskopik dan platform apung yang dapat mengangkat bangunan saat air laut pasang dan saat muka air laut semakin tinggi.

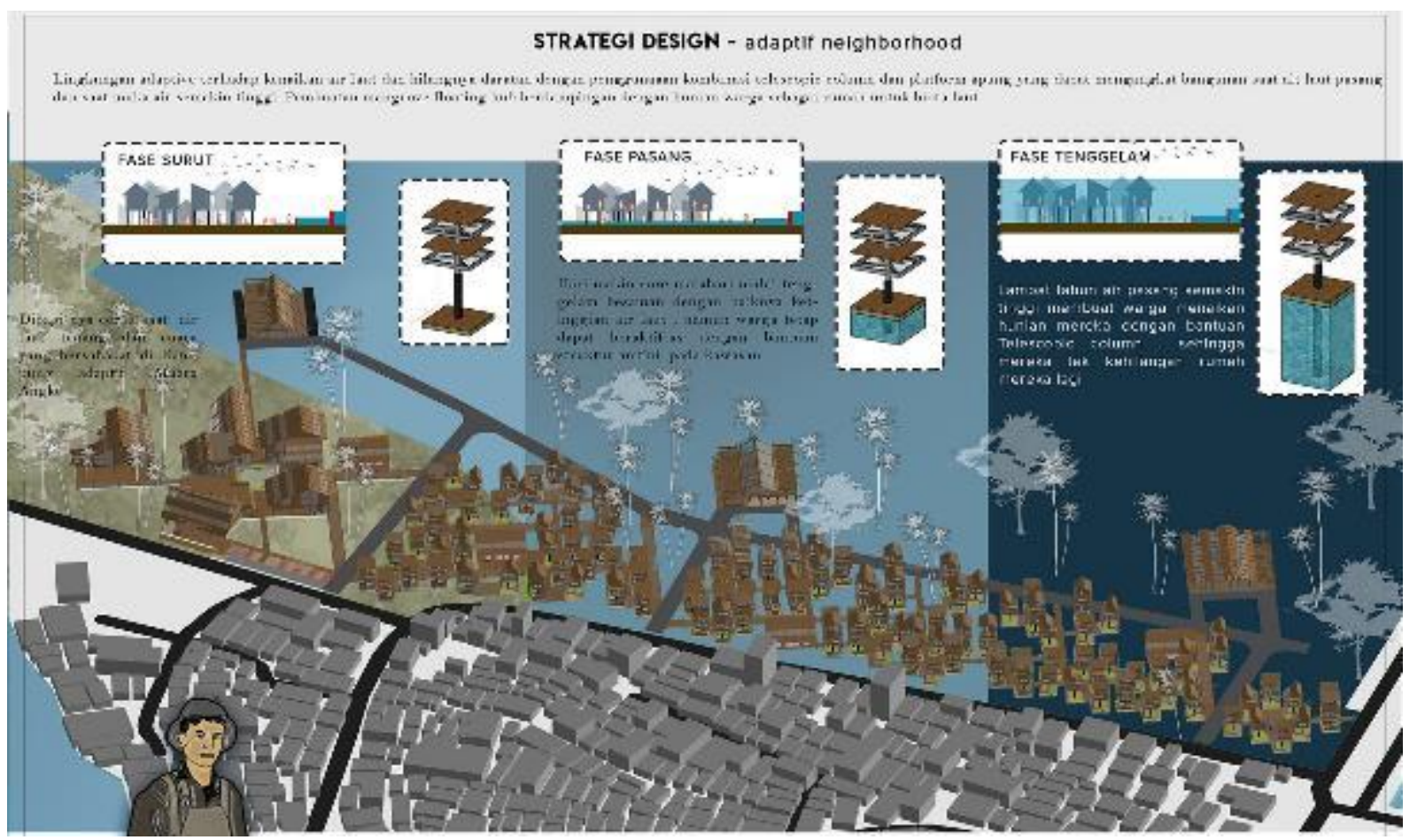

Gambar 9. Strategi Desain

Sumber: Penulis, 2021

\section{Detail Pembuatan Unit Kolom Teleskopik dan Platform Apung Pada Hunian}

Pembuatan unit hunian dibangun secara gotong royong orang warga Kali Adem (Gambar 10), Muara Angke dengan material-material yang mudah dijangkau masnyarakat menengah kebawah. Seperti galon plastic dan papan kayu sebagai material utama bangunan hunian. Pembuatan unit dilakukan dalan tiga langkah utama

(1) Penggalian pondasi, warga bersama-sama melakukan penggalian pondasi $+90 \mathrm{~cm}$ untuk peletakan pondasi. (2) Peletakan kolom, dilanjutkan dengan peletakan kolom teleskopik dan platform apung yang dibuat engan menyatukan galon plastic bekas ukuran $60 \times 90 \mathrm{~cm}$. (3) Penambahan komponen, Warga menambahkan komponen-komponen bangunan lainnya sesuai dengan kebutuhan hunian warga yang disesuaikan dengan pekerjaan mereka.

Detail hunian (Gambar 11) dengan kolom teleskopik dilengkapi dengan pipa teleskopik sebagai penunjang utilitas bangunan hunian dan juga waterbox sebagai tempat penampungan air bersih pada hunian serta stepitank dengan material fiberbox sehingga dapat menggapung bersamaan dengan naiknya bangunan hunian. 


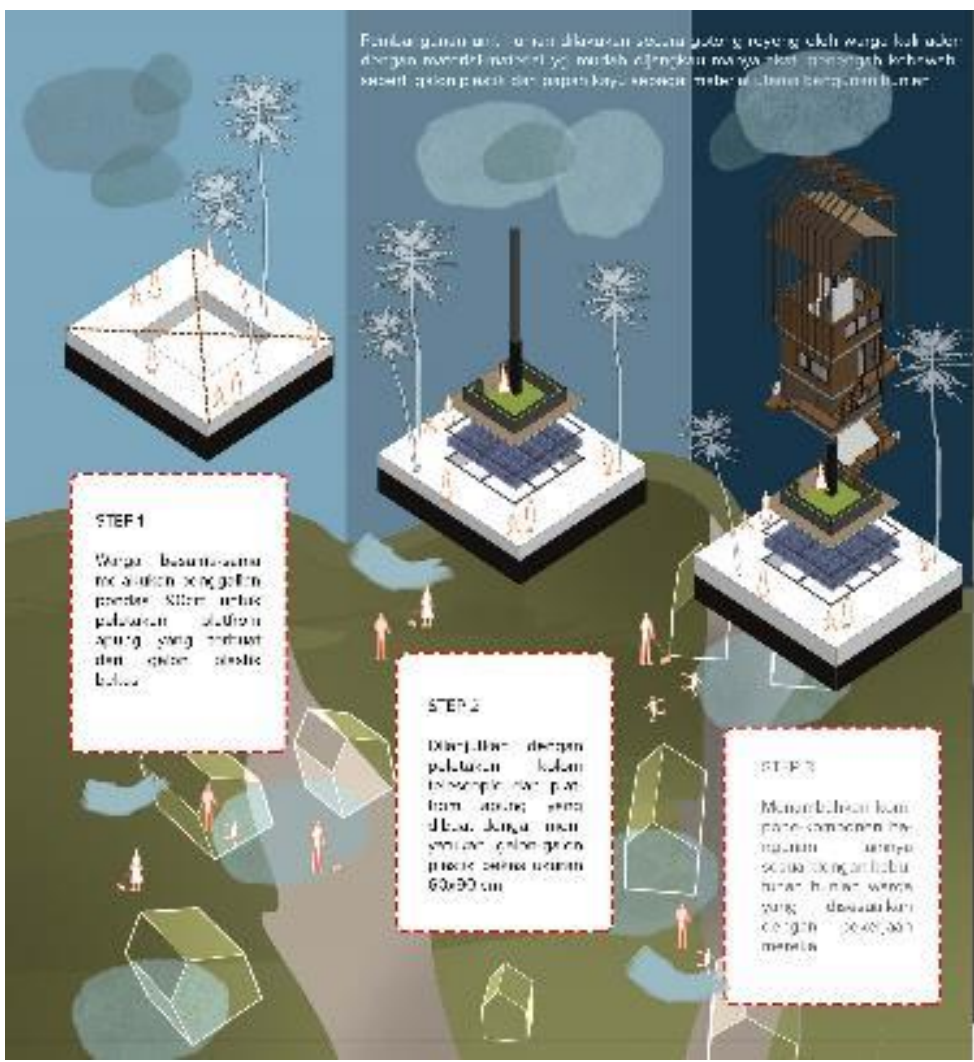

Gambar 10. Diagram DIY Unit

Sumber: Penulis, 2021

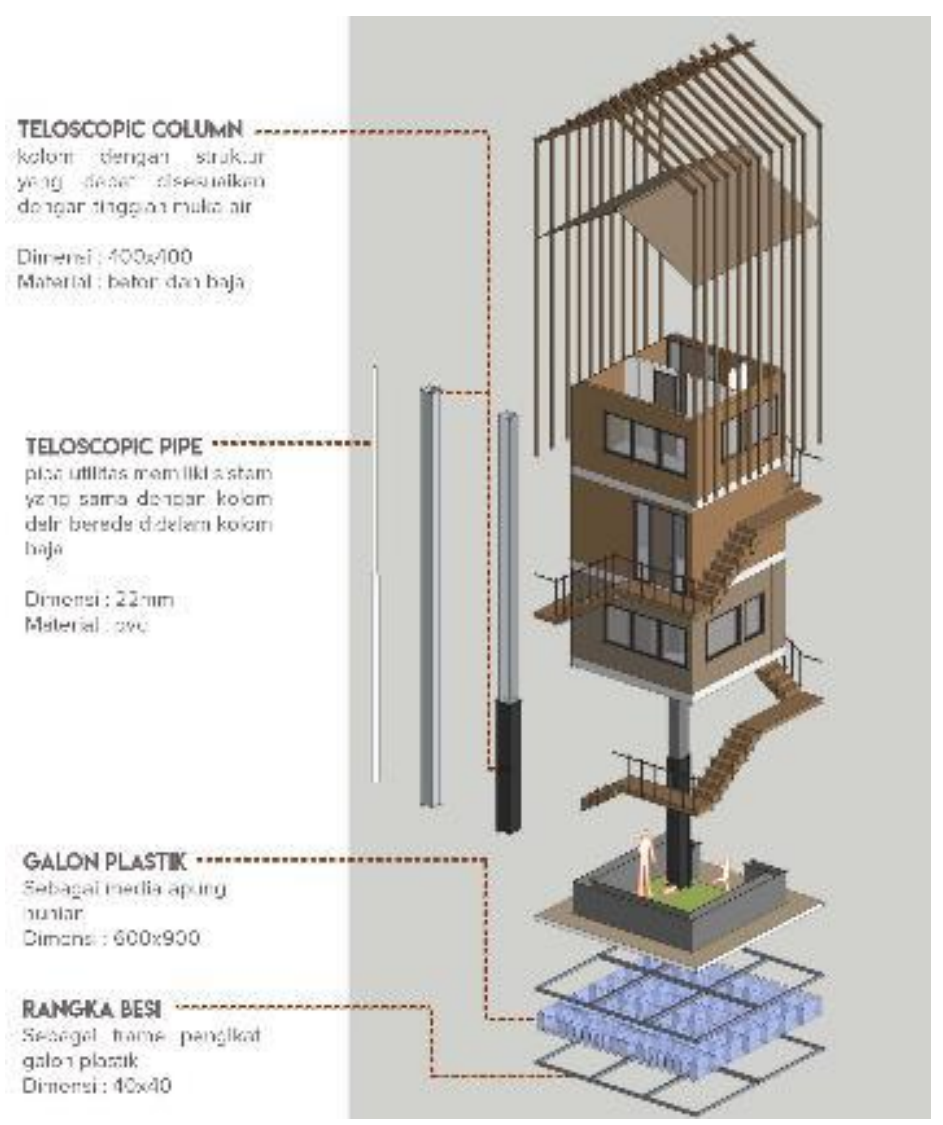

Gambar 11. Detail Hunian

Sumber: Penulis, 2021 


\section{Hasil Desain Rancangan Ekterior dan Interior}

Ekterior dan interior bangunan didominasi penggunaan material kayu pada bagian dinding dan struktur atap bangunan, serta kombinasi bata ringan dibeberapa bidang dinding bangunan. Pada bagian penutup atap menggunakan kombinasi material fiberglass pada area pengeringan ikan dan penunjang hunian agar cahaya matahari dapat masuk dan penggunaan atap lembaran kayu lembaran di bangunan hunian. Struktur atap pada hunian dibuat menerus hingga railing tangga sebagai pengaman sekaligus menjadi kisi-kisi pada fasad bangunan hunian agar lebih menarik (Gambar 12).
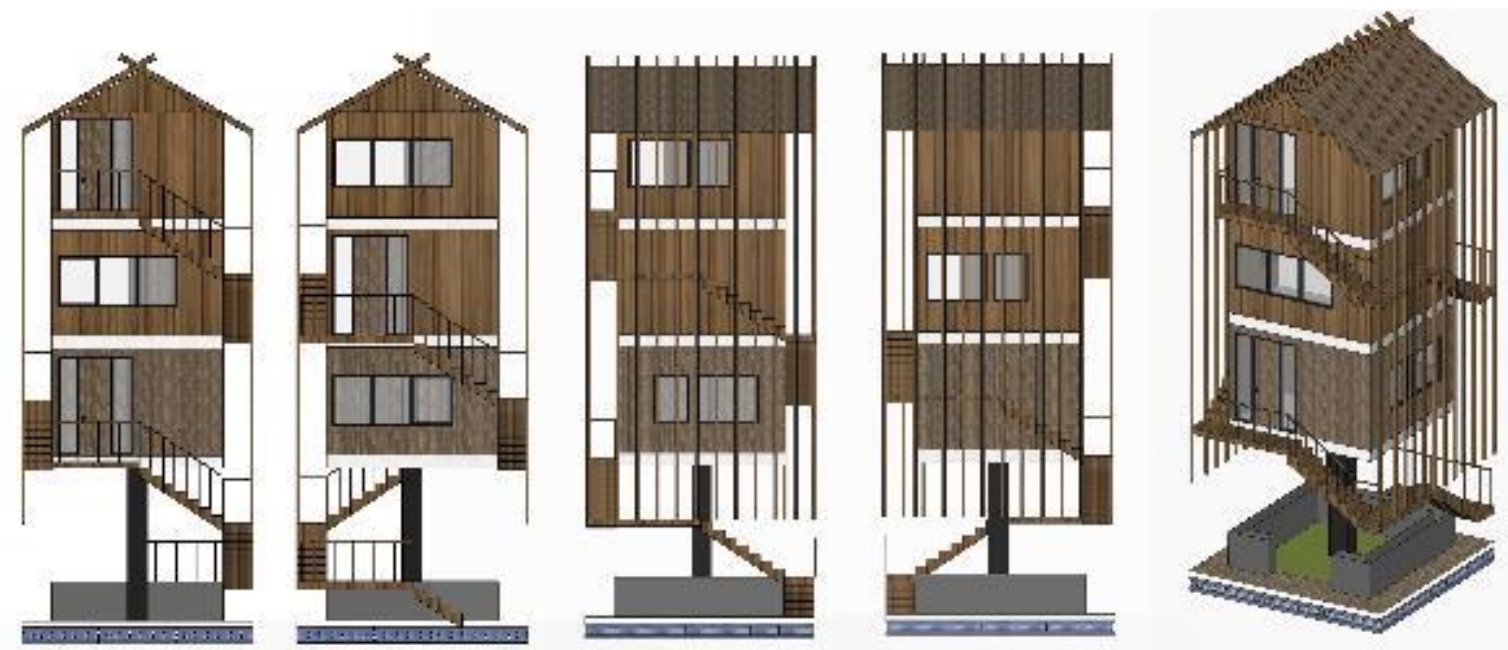

Gambar 12. Struktur Atap Menerus Hingga Railing Sumber: Penulis, 2021

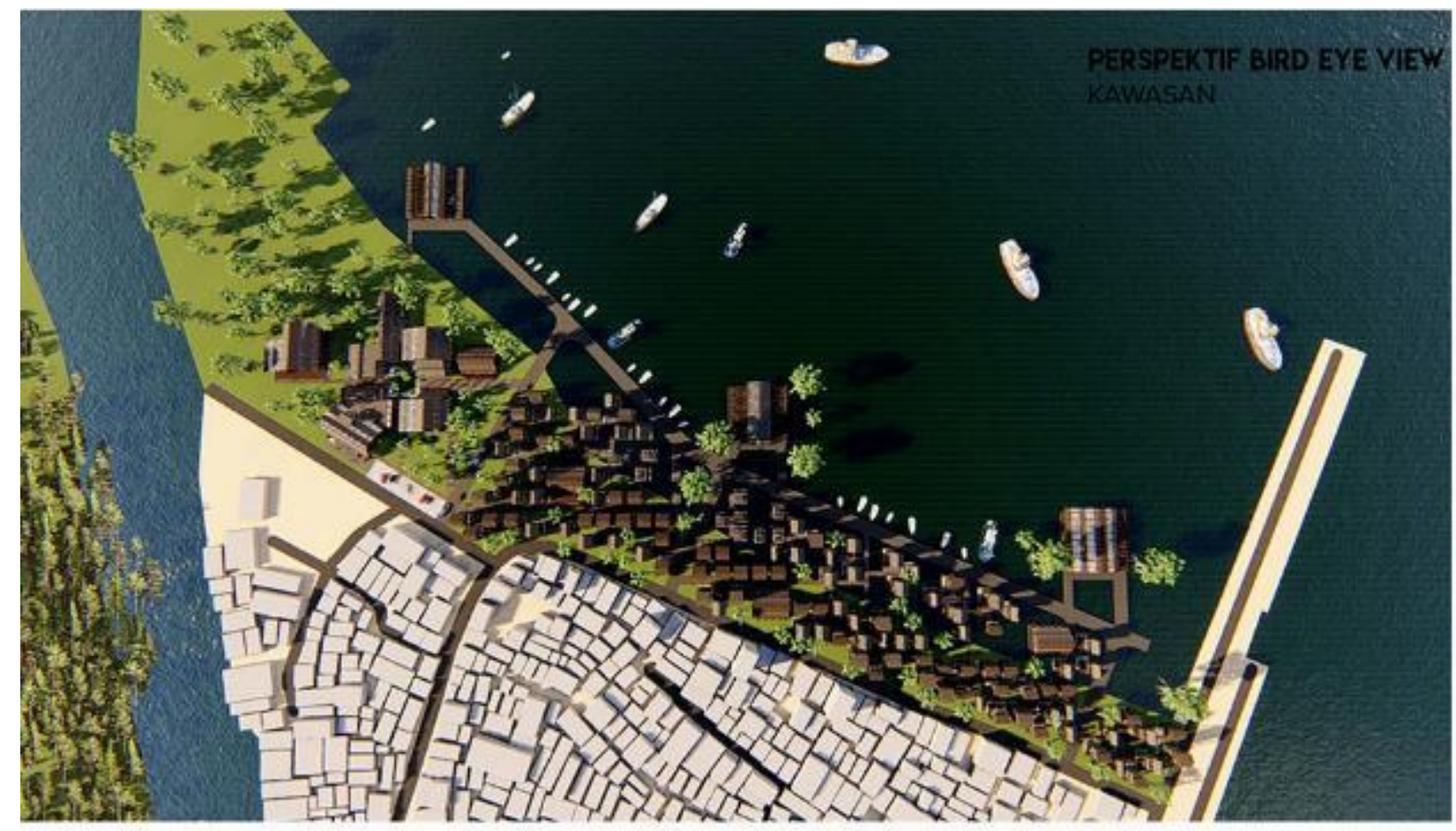

Gambar 13. Perspektif Mata Burung Kawasan

Sumber: Penulis, 2021 


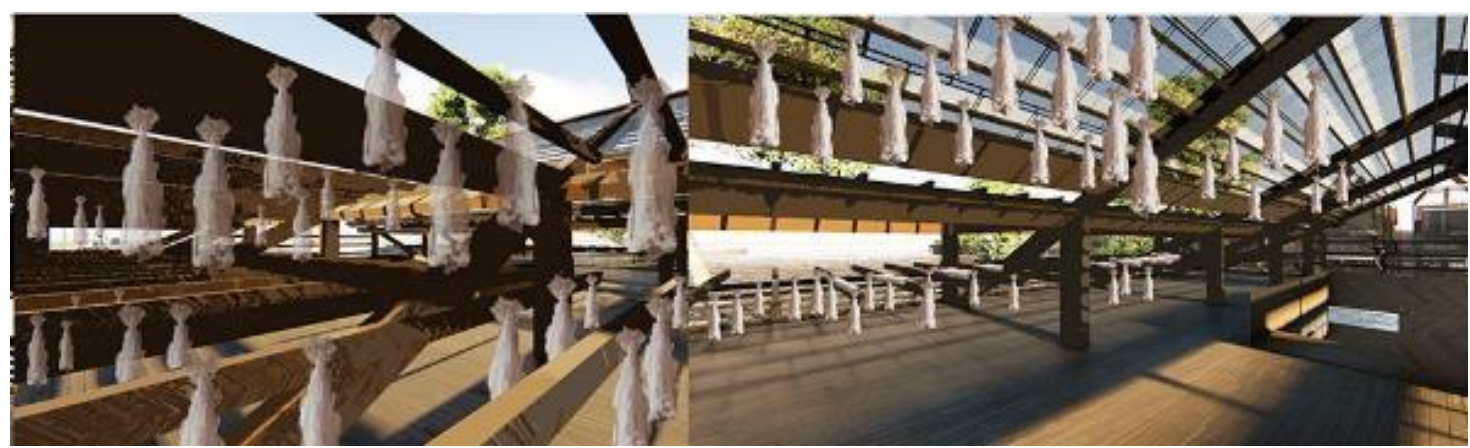

Gambar 14. Perspektif Interior Pengeringan Ikan

Sumber: Penulis, 2021

\section{KESIMPULAN DAN SARAN}

\section{Kesimpulan}

Isu kehilangan daratan pesisir sudah menjadi topik yang banyak dibicarakan, bangunan berupa reklamasi pulau sering kali menjadi jawaban akan isu ini. Sayangnya masyarakat asli pesisir malah terpinggikan atau mengalami penggusuran berulang-ulang demi bangunan hunianhunian mewah dipesisir pantai dengan kapal-kapal pesiar dipinggir hunian mereka. Proyek ini menjawab kebutuhan hunian yang merakyat untuk masyarakat marjinal pesisir pantai yang terlupakan. Proyek ini memberikan kesempatan untuk warga kampung Kali Adem membangun kembali rumah dan tempat mata pencaharian mereka dengan penggunanan teknologi kolom teleskopik dan platform apung yang dapat menyesuaikan dengan kenaikan air laut. Sehingga mereka dapat tinggal dan terus menjalani kehidupan mereka dengan rasa aman dan nyaman di Kali Adem, Muara Angke yang sudah menjadi bagian jadi jati diri mereka.

\section{Saran}

Proyek ini dapat menjadi contoh untuk direplikasi pada area pesisir kota lain yang mengalami permasalahan yang sama. Namun, dengan penyesuaian lokasitas daerah setempat dan ketinggian muka air laut pada area tersebut.

\section{REFERENSI}

AIA.(2018).Salty Urbanism: Sea Level Rise Adaptation Strategies for Urban Areas. Diambil kembali dari: https://www.aia.org/showcases/169556-salty-urbanism-sea-level-riseadaptation-st

Joesidawat, M.(2013).Kajian Perubahan Iklim dan Kenaikan Muka Air Laut di Kawasan Pesisir. Diambil kembali dari : https://www.academia.edu.

Kurniasari,I.(2013) Keberlanjutan Permukiman Nelayan Muara Angke Penjaringan, Jakarta Utara. Diambil kembali dari: http://lib.ui.ac.id/

National Geographic.(2019).Sea level rise article. Diambil kembali dari: http://ocean.nationalgeographic.com/ocean/critical-issues-sea-level-rise

Stefanus,Y dan Sutanto,A.(2019).Wilayah Kampung Nelayan di Muara Angke.Diambil kembali dari : https://journal.untar.ac.id/index.php/jstupa/article/view/3805

Sefrioui S. (2017) . Adapting to Sea Level Rise: A Law of the Sea Perspective. In: Andreone G. (eds) The Future of the Law of the Sea. Springer, Cham. Diambil kembali dari: https://doi.org/10.1007/978-3-319-51274-7 1

The United Nations.(2007).Percentage of world population living near the ocean. Diambil kembali

dari: http://www.un.org/esa/sustdev/natlinfo/indicators/methodology_sheets/oceans_sea s_coasts/pop_coastal_areas.pdf 